\title{
Note from the Editor in Chief
}

\author{
Marina F. Bykova ${ }^{1}$
}

Published online: 5 April 2019

(c) Springer Nature B.V. 2019

With this issue, Studies in East European Thought (SEET) enters its fifty-ninth year of publication, now under the direction of a new editorial team and with a renewed International Advisory Board.

At this juncture, it is appropriate for me, as the new Editor in Chief, to share with you some thoughts about my vision for SEET and its role in the rapidly changing historical and cultural reality. It is also a great opportunity to discuss some of the recent developments and introduce new faces and roles which together will determine the character and affect the scope and operational management of the Journal.

However, before I begin discussing our plans for the future, I would like to thank the former Editor in Chief, Edward Swiderski, for his dedication and outstanding work. Edward led SEET for the past 28 years, and he should be proud of everything that the Journal has achieved in this period. Under his editorship, SEET underwent many substantial changes, becoming more rigorous in the quality of its publication and the selection process. Edward's commitment to the Journal has been truly exceptional. His inspiration and intelligence has served the Journal well by placing it on the map of internationally recognized philosophical journals. Assuming my new role, I want to acknowledge Edward's important contributions to the Journal and express my appreciation for all the efforts that he and his Editorial Board members put into the development and improvement of SEET. Without them the Journal would not be able to accomplish so much. Edward has generously agreed to continue contributing to the Journal as a member of the Advisory Board, and I look forward to our continued collaboration.

The recently renewed International Advisory Board that consists of prominent academics has been expanded to include new members, who, together with returning members, will contribute to the further success of the Journal. I am open to the suggestions and advices of the Board and rely on support of all of its members.

Beginning this year, the Editorial Board also includes three newly introduced Associate Editors, who along with me will play an active role in editing the Journal. All three of them-Vladimir Marchenkov (Ohio University, USA), Lina Steiner (University of Bonn, Germany), and Evert van der Zweerde (Radboud University,

Marina F. Bykova

mfbykova@ncsu.edu

1 Raleigh, USA 
Netherlands) — are well-known scholars working in fields of study relevant to the scope of the Journal. The fact that Associate Editors are based in three different countries and are able to communicate in a number of European languages makes the Journal's environment more inclusive and its operation more efficient. I am very excited about the opportunity to work with such a distinguished group of people, who, like me, see as one of their goals the further growth of SEET and improvement of its ranking and visibility within the intellectual community. The cooperation and responsiveness of the Associate Editor team through the transitional period has been wonderful, and I thank them all for their hard work and guidance. Our immediate practical aims are to increase the number of manuscript submissions, improve the flow of manuscripts through the review and revision process, and ensure a careful following of the production schedule. This is what we are going to pursue together as a team, but we would not be able to succeed in these challenging tasks without helpful assistance from the Board and support of the academic community.

A change in editorship certainly raises questions about the editorial philosophy that will determine the parameters of SEET and guide its work in the coming years. These questions become especially important since we now live in a different world than the one we encountered just a few decades ago. Changes over the last decades, not limited to globalization that coincided with national and cultural diversification, go further and influence how we conceive of the world and the traditional divide between the West and the East. Should this not require narrowing the scope of the Journal, so it could become more specialized? It is my belief that in order for SEET to find its unique niche within thousands of humanities journals, instead of restricting its scope, it must be enhanced to engage different modes of philosophical inquiry by including a range of topics that cross established boundaries among the disciplines.

Building upon the legacy of my prominent predecessors, and supported by a newly established team of Associate Editors, I am committed to strengthening SEET and growing it into a scholarly peer-reviewed philosophical journal with broad scope. This, however, does not mean that SEET will radically change its direction. I am convinced that anything great could be accomplished only if we would preserve the Journal tradition and remain open to the future. We can only hope to be able to meet the challenges of the present and the future if we maintain continuity with the past. To this end, SEET will retain its philosophical core, but it will become more inviting for scholars and scholarly work from other relevant fields of study, most notably those that pursue traditional philosophical questions or use philosophical reflection to address specific disciplinary issues. My Editorial team and I believe in the importance of a truly comprehensive approach to philosophical inquiry, and we welcome submissions from diverse fields, including Slavic, East European, and Eurasian Studies, European history, cultural studies, and many others.

It is also important to overcome a starkly oversimplified opposition between the West and the East that seems to be no longer tenable. The goal of this Journal, as we see it, is to provide a venue for philosophical dialogue free of any ideological polarization and prejudice. SEET does not intend to adopt any specific interpretative agenda or approach. Our objective will be to present impartial scholarly discussion of the philosophical thought and intellectual history of the region known as Eastern 
Europe. SEET will continue to cover different aspects of philosophical and intellectual life-both from historical and contemporary perspectives_-in East and Central Europe, Russia, as well as the post-Soviet states. Our aim is not only to make the philosophical ideas and works of scholars who live in those regions known and accessible to the rest of academic community, but also to nurture a genuine interchange of ideas and information. We see our mission as one of disseminating cutting edge research in order to advance philosophical knowledge. We hope that SEET will attract strong and thought-provoking papers and will be appealing to a broad intellectual audience interested to learn about philosophical development in Eastern and Central Europe as well as in neighboring regions.

Relying on our reviewers and the Advisory Board, as Editors we will ensure our uncompromising commitment to quality. SEET will remain open to authors from all continents and from all relevant disciplines. Our readers and potential authors can be confident that no other consideration, except scholarly merit will influence the decision to publish an article. And in our publication policies, we are going to be as transparent as possible.

Recently SEET was added to the Springer electronic management system known as Editorial Manager (EM), which prompted us to redesign our submission and review process. All communication with the authors has now been channeled through EM, which should optimize the editorial work and enhance the overall experience of our contributors. We will also be refining our editorial practices to reflect these developments. In addition to standard manuscript submissions, we will be looking for new ways to attract outstanding papers. As the Editorial team, we will attempt to capitalize on our familiarity with a variety of the intellectual traditions of the East European region and introduce some thematic issues on specific topics drawn from the ideas and material central to East European philosophical and intellectual concerns. We also welcome proposals for special issues on topics, within the scope of the Journal, that might be of current scholarly interest. All of these, coupled with a rigorous peer review, should enhance the quality of published articles and strengthen the Journal's reputation with the scholarly and general community. We hope to achieve the broadest impact, initiate new discussions, and open up fruitful research engagement with scholars outside the immediate field, thus maximizing exposure to the ideas, concepts, and theories presented in the Journal.

Beginning with this year issue, in addition to publication of original articles, SEET will have a regular book review section, which will give readers an opportunity to sample the range of book-length works on philosophical topics relevant to the scope of the Journal that appear in the West as well as in Eastern European countries. We also plan on publishing translations of original philosophical texts not previously available in English. We trust our readers will find SEET interesting, relevant, and stimulating.

It is a great honor and pleasure for me to serve as the Editor in Chief of Studies in East European Thought. I am very excited about this unique opportunity, and I am prepared for the challenges ahead. In my new role, I plan to dedicate my time to developing proper management for this Journal, and I am looking forward to working very closely with the Associate Editors, the Advisory Board, and the Press in 
order to make the Journal even more successful and to further grow its scholarly reputation.

In conclusion, I would like to say thank you to those who have been helpful in organizing the day-by-day operation of the Journal during the transitional period. I appreciate the Springer system specialists for their invaluable help throughout the EM system implementation period. My thanks also goes to Harini Balasubramanian from the Journal Editorial Office, who oversees the manuscripts submission process, and to the production coordinator, Mariëlle Klijn. I am especially grateful to Cristina dos Santos, the Springer Senior Editor, who has been instrumental in guiding me through many peculiarities of the editorial work and in providing assistance with various important tasks during the still on-going transitional period. Without Cristina's friendly and well-informed advice and constant encouragement and support my first months in the job would have been hardly manageable.

For SEET's success, we all, including myself and the Editorial team, depend on the authors and reviewers who determine the actual content of the Journal. We invite manuscript submissions from both established scholars and budding authors, and we ask for reviewers from different disciplines and academic standings. I truly believe in the power of a team work, and I am confident that only by working together can we improve the Journal's productivity and scholarly impact and achieve the best results.

Let the new chapter of the Journal begin!

Publisher's Note Springer Nature remains neutral with regard to jurisdictional claims in published maps and institutional affiliations. 